\title{
Application of Plaxis Analysis Software For Slope Stabilization For Embankment Instability on Soft Ground Section From Km9 + 820 To Km9 + 960 Projects: The Road Next To The Canal Seven Yards Cad 05 Bridges In Tan Thanh District, Long An Province
}

\author{
*Corresponding Author \\ Le Van Dung

\section{Article History} \\ Received: 18.06 .2020 \\ Accepted: 25.06.2020 \\ Published: 29.06.2020
}

Le Van Dung*, Pham Ba Hung

University of Transport and Communications, Hanoi, Vietnam

\begin{abstract}
The content of this paper focuses on the stability analysis of embankment on soft ground by Plaxis software. Based on the results of actual monitoring of work incidents, make comparisons and recommend the use of the method.
\end{abstract}

Keywords: Slope, safety factor, slip surface, Plaxis.

\section{INTRODUCTION}

When embankment on the road foundation on soft ground, especially in areas with thick soft soil layer located on the surface often causes much subsidence and instability of embankment. In order to serve the assessment of the embankment stability as well as determine the surface of the sliding surface, we often use Bishop's fragmentation method [1]. With this method, the sliding surface form must be predetermined according to certain shapes, leading to many limitations [2].

Plaxis software analyzes slope stability based on a theoretical basis different from Bishop's fragmentation method, which is a method of attenuation of shear strength [1]. With this method we do not need to assume a slip surface but calculate the stress-strain with $\mathrm{c}$-dần decreasing (by dividing $\mathrm{c}-\varphi$ by $\mathrm{K}$ ) to see the plastic deformation elements growing gradually and leading to slope slope is unstable when the displacement of points on the slope surface increases sharply.

\section{THEORETICAL BASIS}

Determination of slope stability coefficient by the Plaxis software

The slope stabilization coefficient is the $\Sigma \mathrm{Msf}$ coefficient calculated by formula (1)

$$
\sum M s f=\frac{\varphi_{\text {imput }}}{\varphi_{\text {reduced }}}=\frac{c_{\text {imput }}}{c_{\text {reduced }}}
$$

Here, the durability parameters with the index on "input" are the input parameters in the data entry and the index parameters under "reduced" are the values that are gradually reduced during the analysis. The $\Sigma$ Msf coefficient is assigned from the value 1.0 at the beginning of the calculation and the Msf increment (Msf's increment) is pre-assigned and it represents the increase in durability degradation compared to the first calculation step, the number This has defaulted to 0.1 (each change has a value of 0.1 ) [3,4]. The durability parameter is continuously reduced automatically until the total number of pre-defined calculation steps is completed. The slope is calculated as unstable when $\Sigma$ Mcf is less than one $[5,6]$.

Copyright @ 2020: This is an open-access article distributed under the terms of the Creative Commons Attribution license which permits unrestricted use, distribution, and reproduction in any medium for non commercial use (NonCommercial, or CC-BY-NC) provided the original author and source are credited. 
The calculation of slope safety factors by this method results in an $8 \%$ to $13 \%$ smaller than Bishop's fragmentation method [7], another study showed that the result was less than $0.8 \%$ to $1.5 \%$ [4, 5]. As a result, this is a more reliable and secure method than the Bishop fragmentation method we often use.

\section{Determine the shape of slip surface by Plaxis software}

When it comes to the sliding surface, we think of a section where two parts of the landslide on each other and if a certain soil element is slipped through, the element is cut in two parts (Figure-1). With the assumption that the sliding block is absolutely hard and rotates around the center of the sliding arc, the closer the slide position to the sliding surface, the greater the total displacement. On that basis, many views have predicted that the sliding shear lies in the region with the largest total shear strains when auditing stability by Plaxis software (Figure-2).

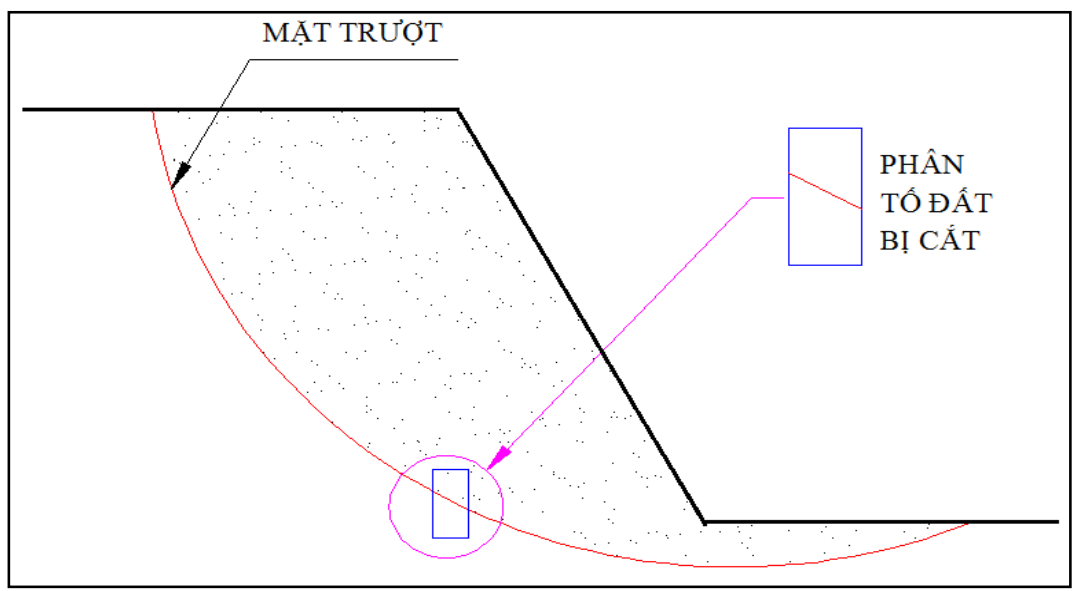

Fig-1: Model of sliding surface

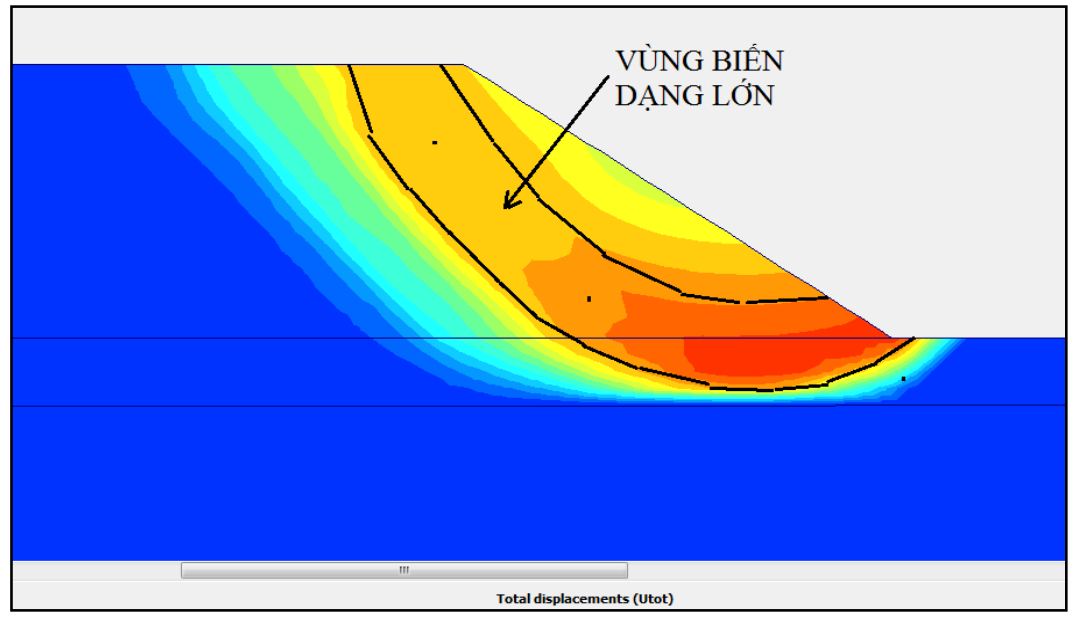

Fig-2: A graph of displacement values in the Plaxis

However, if using the Plaxis software to forecast the sliding supply as mentioned above encountered some unreasonable such as:

- In fact, the sliding block is not absolutely hard, but it itself is deformed when displaced. Therefore, the point in the sliding block with the largest displacement is not necessarily on the sliding surface (Figure-3).

- The Plaxis software is built on finite element theory, which means that the ground is divided into "Elements". In the process of calculating the elements can be deformed but always guaranteed the link between them. Therefore, the magnetic parts near the sliding surface in contact with the non-displaced magnetic parts under the sliding surface will have smaller displacements than other elements in the sliding mass, but these magnetic sections have large shear deformation (Figure-4).

From the above arguments, the author proposes a parameter to predict shear supply by the Plaxis software based on Total Shear strains. 
The shear is the ratio of the horizontal displacement to the original length of the element and is calculated using the formula (2):

$$
\gamma=\frac{\Delta x}{L}
$$

In which:

$\gamma$ - Shear deformation;

$\Delta \mathrm{x}$ - Horizontal displacement (Figure-1);

$\mathrm{L}$ - Initial length of the element (Figure-1).

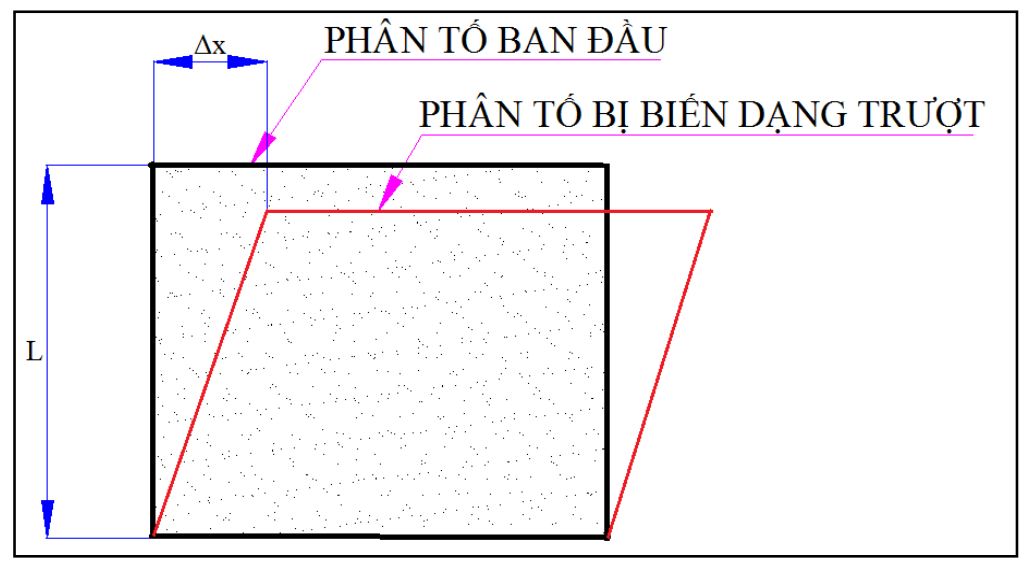

Fig-3: Deformed object was cut

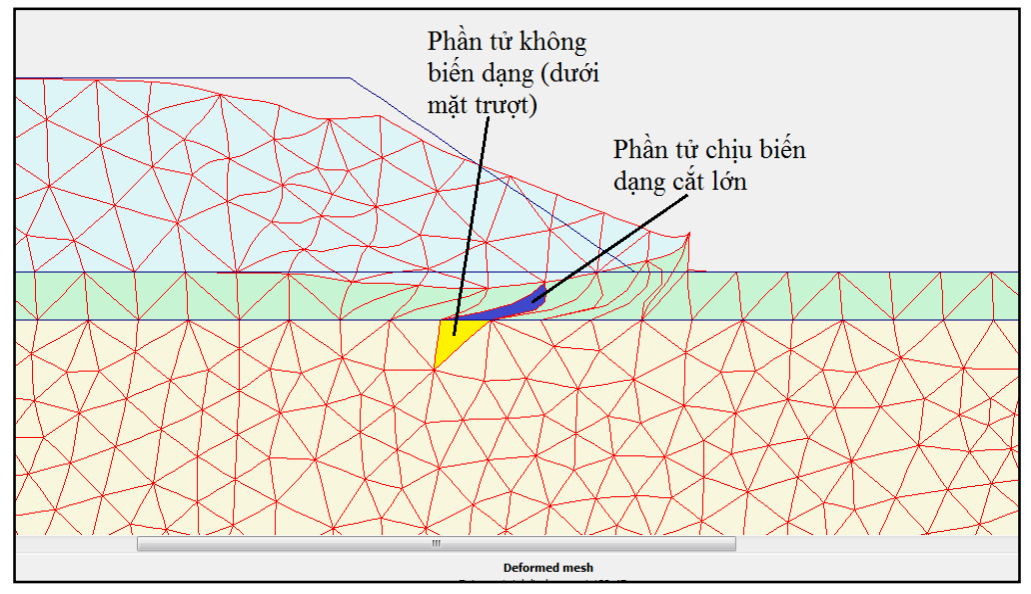

Fig-4: Section of shear strain in the Plaxis

\section{OVERVIEW OF THE PROJECT AND THE INCIDENT}

The project of constructing the Road next to Bay Thuoc canal and 05 bridges (DT.837B) was approved by the Chairman of Long An Provincial People's Committee in Decision No. 3475 / QD-UBND dated September 25, 2017. The route has a total length of $16,021 \mathrm{~km}$, designed according to the standard Grade V plain road (TCVN4054-2005), the project implementation period 2017 to 2020, the route consists of 05 bridges.

Incidents of embankment instability occurred at KM9 + 820 to KM9 + 960 of package $5 \mathrm{~b}$. Up to the time of the incident (January 6, 2020), the project was basically completed, only completed works were completed.

Survey results and field measurements showed that $[5,6]$ :

- $\quad$ The length of the fault area is 140m from KM9 + 820 to KM9 + 960 (Figure-7);

- The largest vertical displacement after failure is $2.97 \mathrm{~m}$ at KM9 + 880 (Figure-6);

- The leg of the road on the left (lotus pond) is sliding to the right (Bay Thuoc canal) at KM9 +880 is $0.73 \mathrm{~m}$ (Figure-6);

- The right side of the road on the right slide toward the biggest Bay Thuoc is $2.49 \mathrm{~m}$;

- On the channel side, there are phenomena of emergence (Figure-5).

- From the results of observations and measurements in the field, the author expected the sliding surface (Figure-8). 


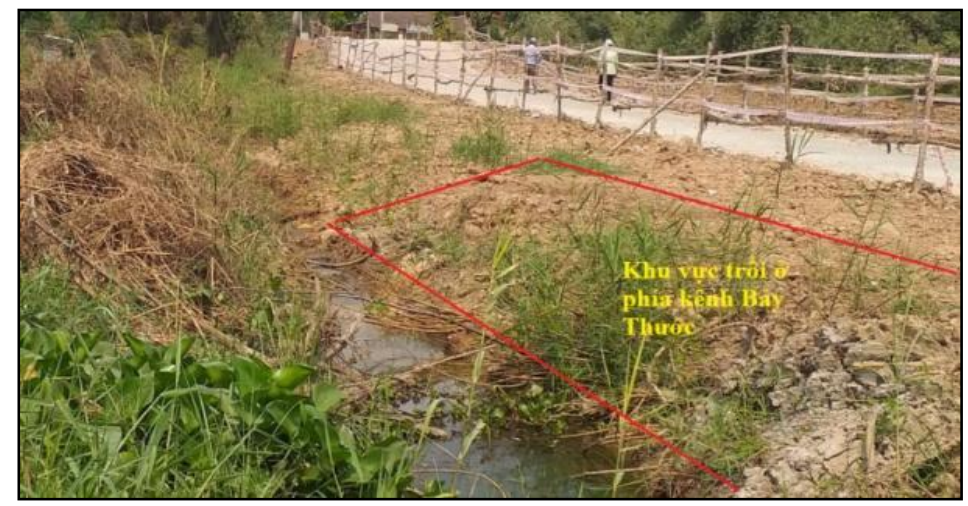

Fig-5: The bulging area

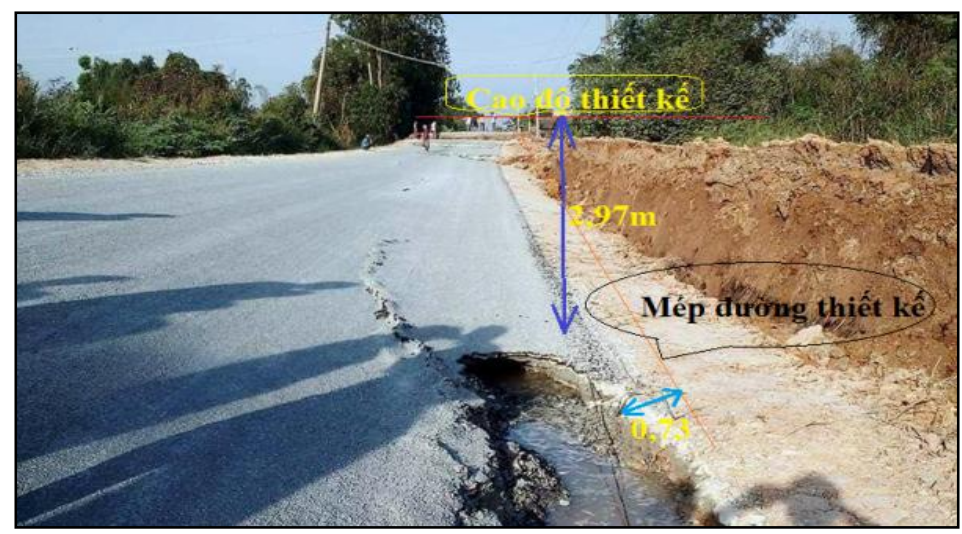

Fig-6: Recorded distortion

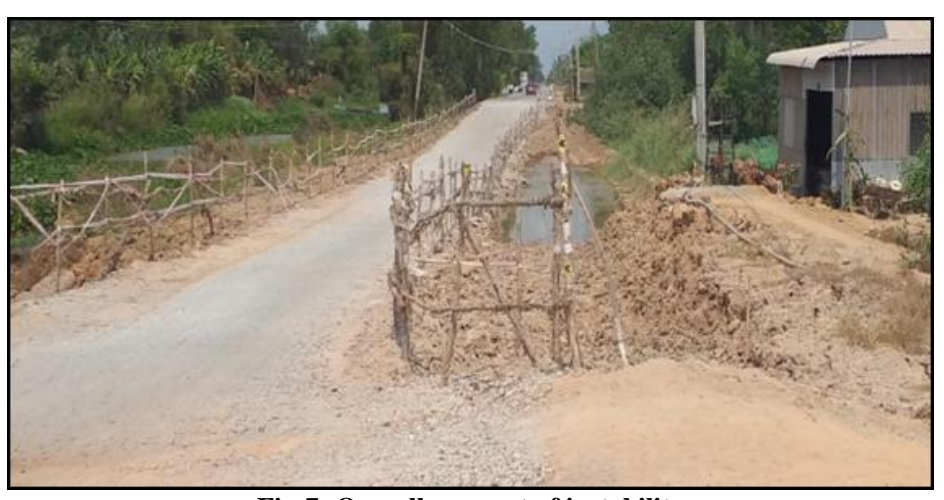

Fig-7: Overall segment of instability

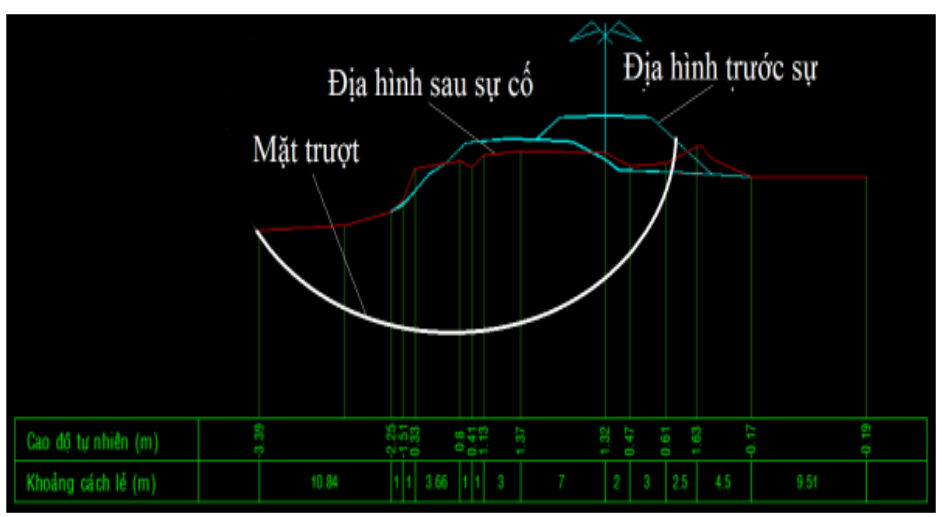

Fig-8: The slip surface noted 


\section{ANALYSIS OF SLOPE STABILITY BY THE PLAXIS SOFTWARE \\ Calculation Parameters}

According to the results of additional geological survey and engineering design, the calculated cross-sectional geological structure is shown in Figure-9 [2].

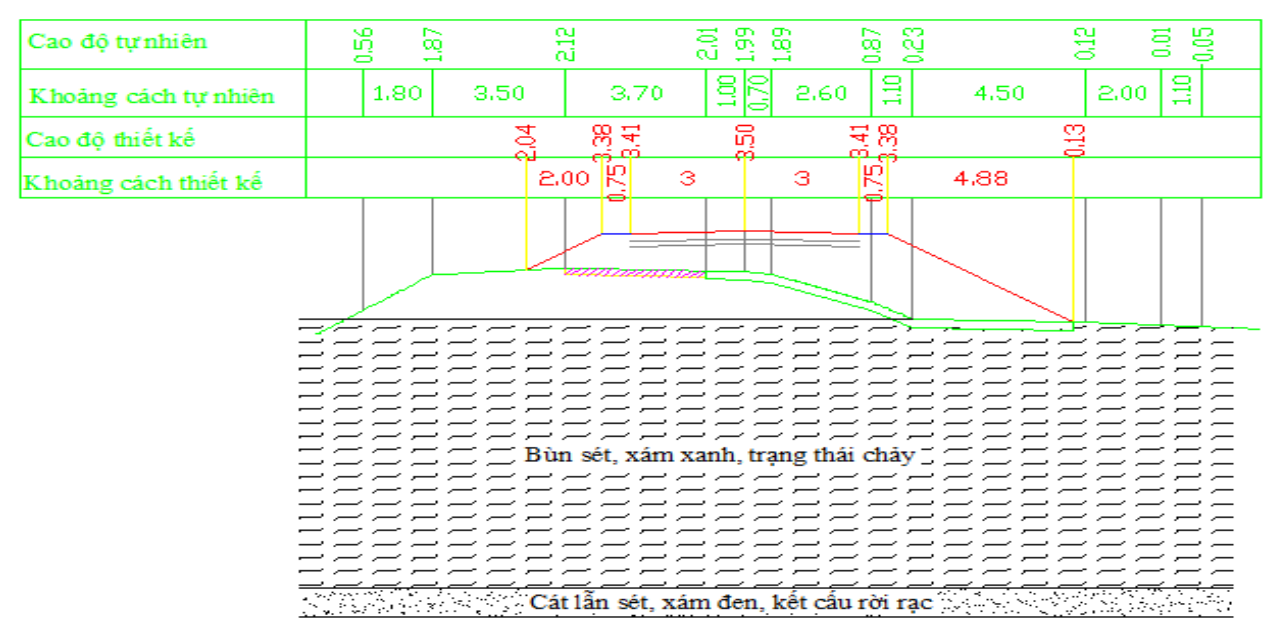

Fig-9: Cross-section of calculated geological structure

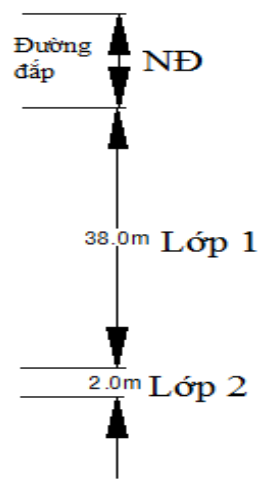

Mechanical properties of the material layers are shown in Table $1[2,6]$.

Table-1: Physical and mechanical properties and models of material layers

\begin{tabular}{|c|c|c|c|c|c|c|c|c|c|c|}
\hline \multirow[t]{2}{*}{ STT } & \multirow[t]{2}{*}{ Lớp } & \multirow[t]{2}{*}{ Mô hình } & $\gamma_{\mathrm{sat}}$ & $\gamma_{\text {unsat }}$ & $\mathbf{K}_{\mathbf{x}}$ & $\mathbf{K}_{\mathbf{y}}$ & c & $\varphi$ & $\boldsymbol{v}$ & $\mathbf{E}$ \\
\hline & & & $\mathrm{kN} / \mathrm{m}^{3}$ & $\mathrm{kN} / \mathrm{m}^{3}$ & m/ngày & m/ngày & $\mathbf{k P a}$ & Độ & - & $\mathbf{k P a}$ \\
\hline 1 & NĐ & $\mathrm{MC}$ & 19.1 & 18.60 & $2.0 \mathrm{E}-5$ & $1.0 \mathrm{E}-5$ & 17.0 & 15.1 & 0.3 & 42000 \\
\hline 2 & Lớp 1 & $\mathrm{MC}$ & 15.3 & 15.02 & $5.4 \mathrm{E}-5$ & $2.7 \mathrm{E}-5$ & 12.3 & 0.5 & 0.35 & 960 \\
\hline 3 & Lớp 2 & $\mathrm{MC}$ & 18.9 & 18.50 & 0.04 & 0.02 & 10.3 & 16.0 & 0.3 & 2976 \\
\hline
\end{tabular}

\section{CALCULATION RESULTS}

A graph of the total displacement (Total displacements) and the total shear straints (Total Shear straints) when analyzing stability (Phi / c reduction) is shown in Figure 10 and11.

Slope stability coefficient $\Sigma \mathrm{Mfs}=0.814$ (Figure-12) and strain network (Figure-13)

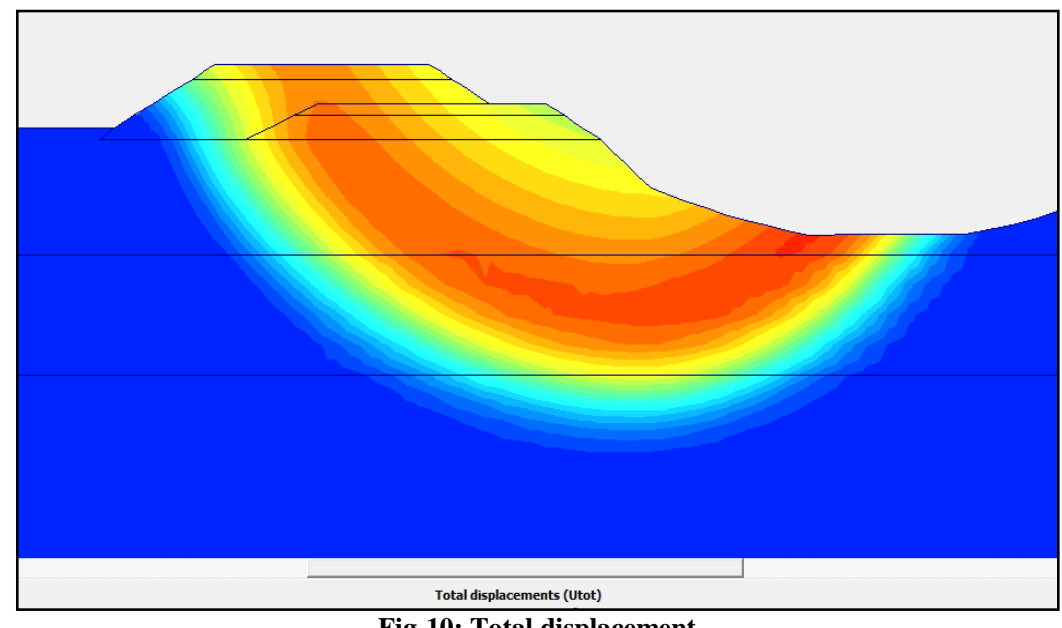

Fig-10: Total displacement 


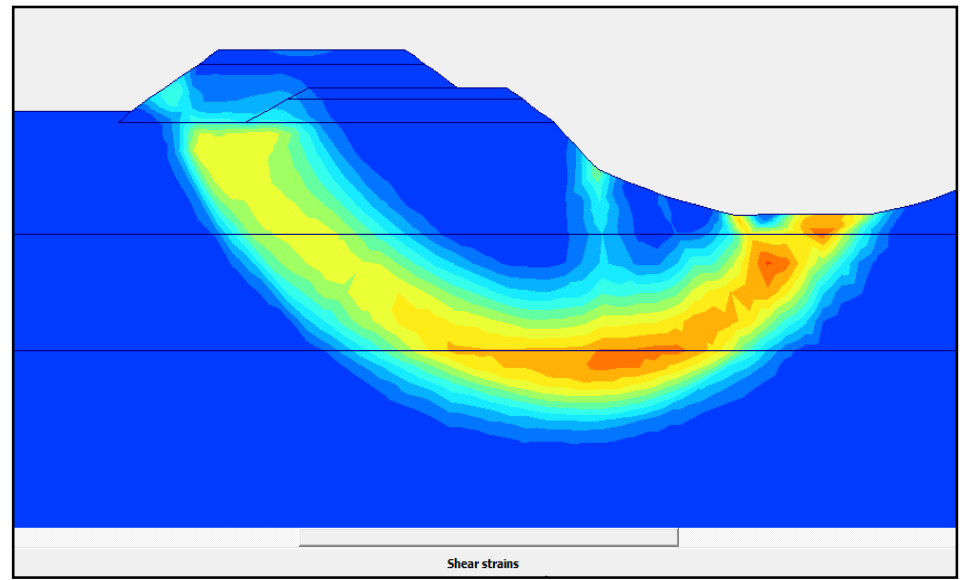

Fig-11: Total shear strain

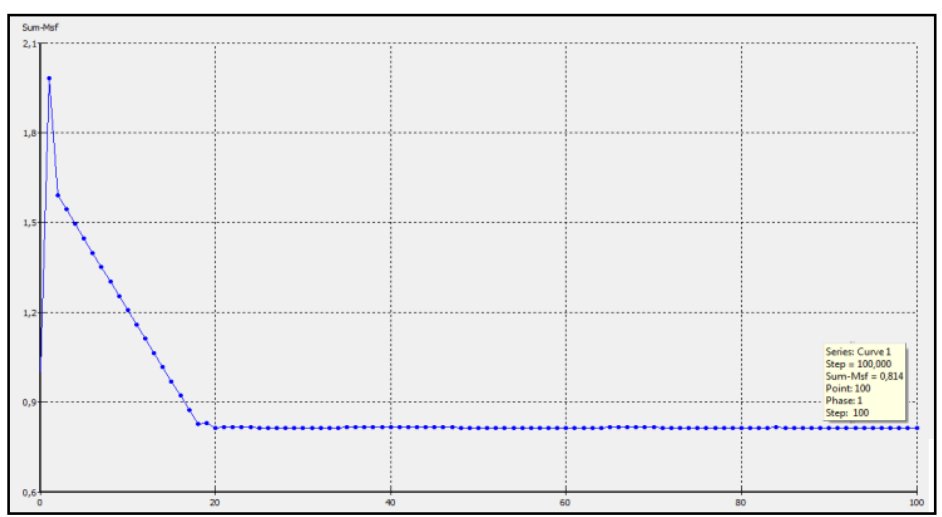

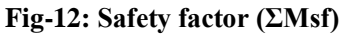

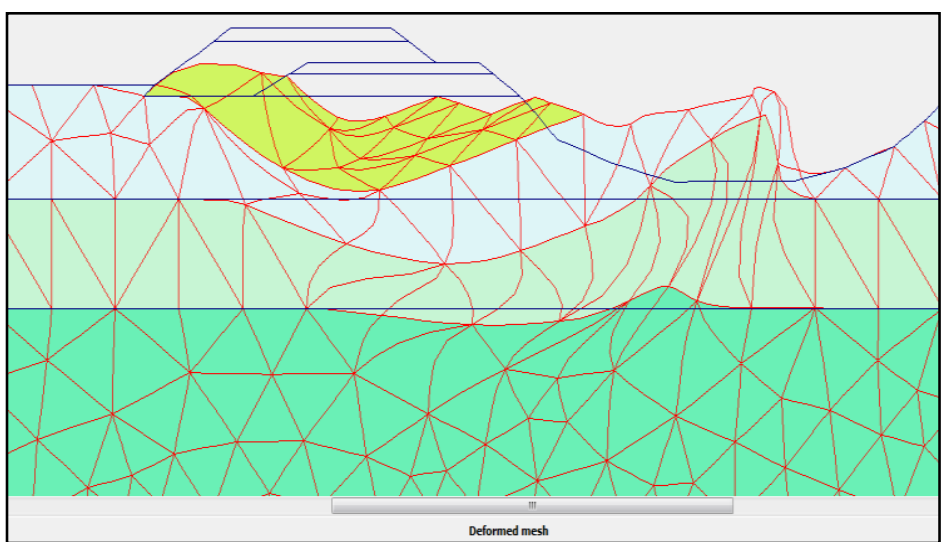

Fig-13: Deformation grid

\section{Comment on the analysis results}

- The slope safety factor calculated $\Sigma \mathrm{Mfs}=0.814$, this value is less than 1.0 so the slope is slipped.

- Forecast of the shear surface according to the total shear strain and the deformation emerging on the channel according to the deformation grid for realistic close results (Figure-14). 


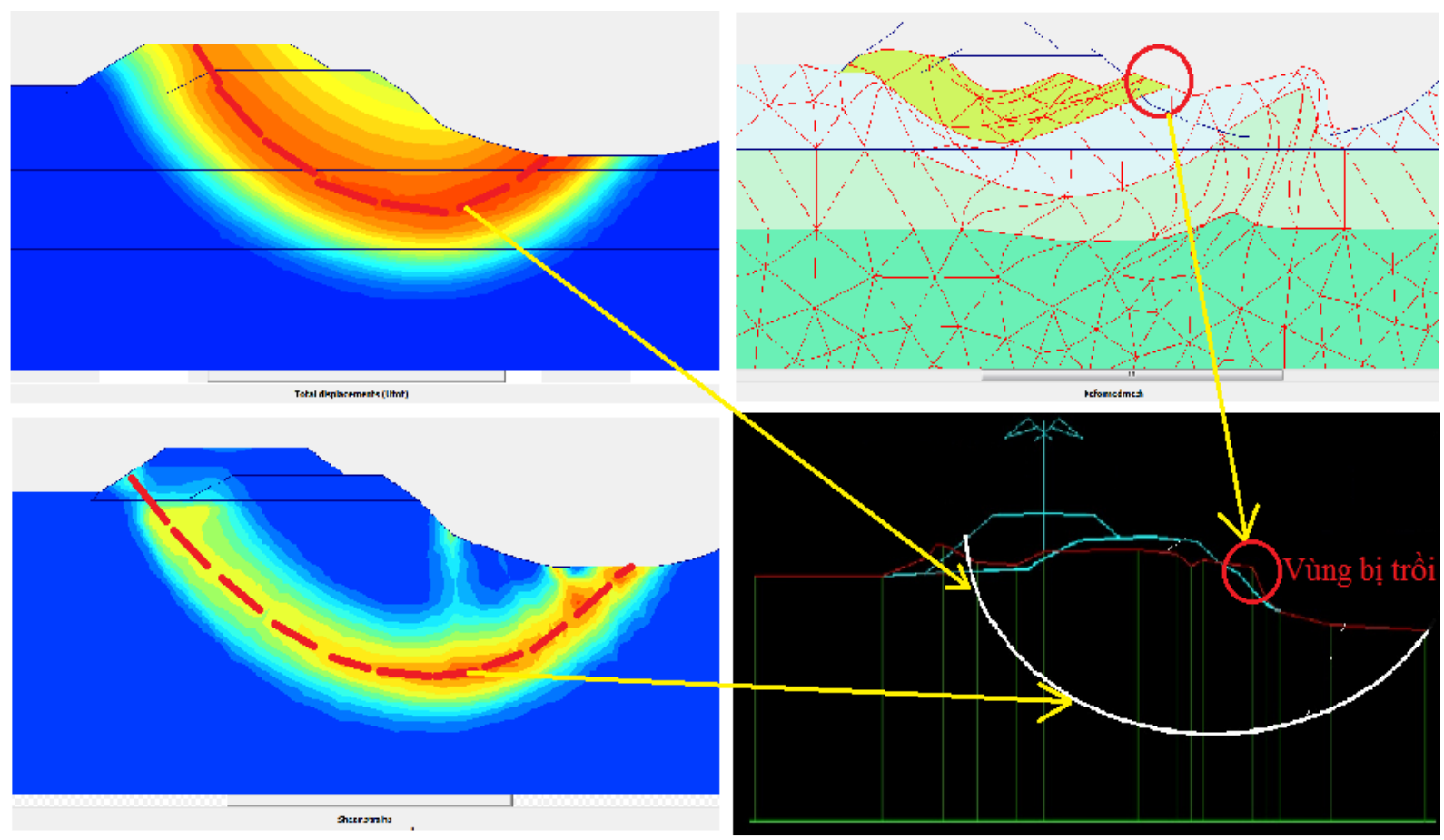

Fig-14: Forecast of slip surface according to maximum displacement and maximum shear strain

\section{CONCLUSION}

The slope safety factor calculated $\Sigma \mathrm{Mfs}=0.814$, this value is less than 1.0 so the slope is slipped, this result is consistent with the theoretical basis of the method. Provisions in 22TCN262-2000, calculated by the method of Bishop slope fragmentation is only considered stable when this value is greater than 1.2.

The sliding surface is forecasted at the face with the maximum total shear strains maximum results very close to the actual observed. Whereas, forecasting slip surface at the surface with the largest total displacement (Total displacements) has the largest result of large difference.

The deformed area on the channel side is forecasted by the software according to the deformation grid target to coincide with the actual deformation area.

\section{REFERENCES}

1. Ministry of Transport. (2000). 22TCN262-2000 - Survey process of designing embankment road foundation on soft ground - design standards.

2. Nam Khang Consulting Joint Stock Company. (2020). Additional geological survey of works: Road pair of Bay Thuoc canal and 05 bridges (DT.837B).

3. Dinh, B. A. (2006). Soil Mechanics. Hanoi: Transport.

4. Quang, N. T., Tung, N. T., \& Linh, C. T. (2018). Comparison of current methods of stability analysis on earth dams. Journal of Science and Technology, University of Danang, 9(130):51-55.

5. Center of Transportation Science Research and Technology Development. (2020). Results of the evaluation of cause of construction failure: Roads of Bay Thuoc canal and 05 bridges (DT.837B).

6. Monetary Policy Center. (2020). Survey results, measurement of the status of the work after the incident.

7. Hung, L. Q. (2018). Assessing the possibility of using Plaxis software in railway platform stability analysis. Transport Journal, 5(4):34-43. 